\title{
Moderate increases in daily step count are associated with reduced IL6 and CRP in women with PCOS
}

\author{
M A Webb ${ }^{1,2}$, H Mani, ${ }^{3,4,5}$, S J Robertson'2, H L Waller ${ }^{3}$, D R Webb ${ }^{1,3}$, C L Edwardson ${ }^{1,3}$, D H Bodicoat ${ }^{1,3}$, T Yates ${ }^{1,3}$, \\ K Khunti $^{1,2,3}$ and M J Davies ${ }^{1,2,3}$
}

${ }^{1}$ NIHR Leicester-Loughborough Diet, Lifestyle and Physical Activity Biomedical Research Unit, University Hospitals of Leicester, Leicester General Hospital, Leicester, UK

${ }^{2}$ The Leicester Diabetes Centre, University Hospitals of Leicester NHS Trust, Leicester General Hospital, Leicester, UK ${ }^{3}$ Diabetes Research Centre, University of Leicester, Leicester General Hospital, Leicester, UK

${ }_{4}^{4}$ Department of Diabetes and Endocrinology, Leicester Royal Infirmary, University Hospitals of Leicester NHS Trust, Leicester, UK

${ }^{5}$ Diabetes and Endocrinology Department, Kettering General Hospital NHS Foundation Trust, Kettering, UK

Correspondence should be addressed to H Mani: hamidreza.mani@kgh.nhs.uk

\begin{abstract}
Aims: Physical activity has been proposed to be an effective non-pharmacological method of reducing systemic inflammation and therefore may prove particularly efficacious for women with polycystic ovary syndrome (PCOS) who have been shown to have high levels of inflammation and an increased risk of type 2 diabetes (T2DM) and cardiovascular disease (CVD). Therefore, the aim of the present study was to assess whether modest changes in daily step count could significantly reduce levels of inflammatory markers in women with PCOS.

Subjects and Methods: Sixty-five women with PCOS were assessed at baseline and again at 6 months. All had been provided with an accelerometer and encouraged to increase

Key Words
- polycystic ovary syndrome
- interleukin 6
- C-reactive protein
- inflammation
- step count
- accelerometer
- physical activity
activity levels. Multivariate linear regression analyses (adjusted for age, ethnicity, baseline step count, change in BMI and change in accelerometer wear-time) were used to assess changes in daily step count against clinical and research biomarkers of inflammation, CVD and T2DM.

Results: Mean step count/day at baseline was $6337( \pm 270)$. An increase in step count (by 1000 steps) was associated with a $13 \%$ reduction in IL6 $(\beta:-0.81 \mathrm{ng} / \mathrm{L} ; 95 \% \mathrm{Cl},-1.37,-0.25$, $P=0.005)$ and a $13 \%$ reduction in CRP $(\beta:-0.68 \mathrm{mg} / \mathrm{L} ; 95 \% \mathrm{Cl},-1.30,-0.06, P=0.033)$. Additionally, there was a modest decrease in BMI $\left(\beta: 0.20 \mathrm{~kg} / \mathrm{m}^{2} ; 95 \% \mathrm{Cl},-0.38,-0.01\right.$, $P=0.038$ ). Clinical markers of T2DM and CVD were not affected by increased step count. Conclusions: Modest increases in step count/day can reduce levels of inflammatory markers in women with PCOS, which may reduce the future risk of T2DM and CVD.

\section{Introduction}

Polycystic ovary syndrome (PCOS) is the most common endocrine condition in women of reproductive age with a reported prevalence of up to $18 \%$ (1). Symptoms of PCOS include excess hair, irregular/absent periods and infertility. Reports estimate that approximately $77 \%$ are insulin resistant, 35\% exhibit impaired fasting glucose and 10\% have type 2 diabetes (T2DM) $(2,3)$. Furthermore, it is estimated that women with PCOS have a two-fold increased risk of coronary heart disease and stroke and $43 \%$ have metabolic syndrome $(4,5,6)$.
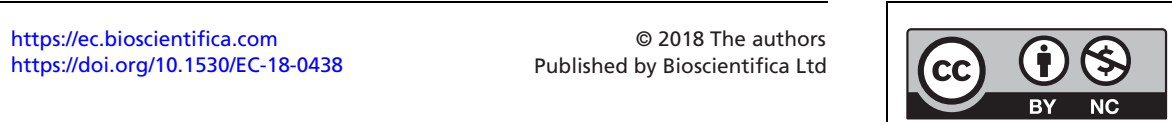
Although the increased risk of cardiovascular disease (CVD) and T2DM is, in part, due to many women with PCOS being overweight, the increased risk is also associated with the high levels of systemic inflammation seen within this group $(7,8)$. In particular, the inflammatory cytokine IL6 has been found to be higher in women with PCOS compared with those without and further studies have reported that the higher IL6 levels directly contribute to insulin resistance $(9,10)$. Indeed experimental studies in healthy subjects have demonstrated that IL6 injections increase blood glucose without any changes in C-peptide levels, suggesting that IL6 directly reduces insulin sensitivity (11). IL6 also modulates the transcription of C-reactive protein (CRP) and indeed CRP levels have been reported to be $95 \%$ (CI 71-122\%) higher in women with PCOS compared with healthy controls (7). As well as being a marker of generalised inflammation, CRP has been shown to be a highly accurate predictor of future heart disease with, $0-1 \mathrm{mg} / \mathrm{L}$ predicting $<6 \%$ risk of a cardiovascular event in the next 10 years (low risk), $1-3 \mathrm{mg} / \mathrm{L}$ predicting a $6-20 \%$ risk (average risk) and $>3-10 \mathrm{mg}$ predicting $>20 \%$ risk (high risk) (12). Taken in combination it could be postulated that driving down levels of IL6 and CRP could reduce risk of both T2DM and CVD in women with PCOS.

In the field of PCOS, the implementation of vigorous intensity exercise interventions has been linked to a reduction in the inflammatory state (13). Bicycle training 3 times per week with an average $\mathrm{VO}_{2}$ max of $67 \%$ was associated with a $16.5 \%$ reduction in CRP $(1.88-1.57 \mathrm{mg} / \mathrm{L})$ in young women with PCOS (13). However, evidence suggests that interventions that encourage walking and do not require attendance at a facility are most likely to lead to sustainable increases in overall physical activity (14). Therefore, the aim of the present study was to assess whether modest changes in daily step count can have a significant positive impact on the metabolic health of overweight women with PCOS.

\section{Subjects and methods}

The current study is a secondary analysis of the Structured Education Programme to Improve Cardiovascular Risk in Women with Polycystic Ovary Syndrome (SUCCESS) clinical trial, (Clinical Trials registration number: NT01462864) (15). Ethical approval was obtained from the East Midlands' Research Ethics Committee (reference number: 11/EM/0141) and informed consent of the participants was obtained after the nature of the procedures had been fully explained. The SUCCESS trial compared https://ec.bioscientifica.com

https://doi.org/10.1530/EC-18-0438 (c) 2018 The authors Published by Bioscientifica Ltd structured education (with the aim increasing daily step count) with standard care, which included written advice about what PCOS is and the benefits of losing weight and a healthy lifestyle, a full description of the SUCCESS trial has been described elsewhere (15). Increases and decreases in physical activity were seen across both groups therefore for the purpose of this study randomisation was not taken into account. The aim of the present study was to assess the impact of changes in daily step count over a 6-month period on markers of: inflammation (IL6 and CRP), T2DM (glucose, HbA1c and insulin) and CVD (blood pressure and cholesterol).

\section{Participants}

Women with a confirmed diagnosis of PCOS (16) BMI ( $\geq 23 \mathrm{~kg} / \mathrm{m}^{2}$ for black and minority; $\geq 25 \mathrm{~kg} / \mathrm{m}^{2}$ for white Europeans) (17) aged 18-49 years inclusive, who had stable PCOS treatment in the previous 6 months were eligible. Exclusion criteria were pregnancy, diabetes, use of corticosteroids, a disabling physical or mental condition and inability to speak English. The SUCCESS study recruited a total of 161 participants and for the purpose of this study participants from the intervention and control arms were pooled. However, of the 161 participants, 82 were excluded from this analysis due to missing/invalid pedometer measurements $(n=79)$ and/or due to blood samples not being taken at either baseline or follow-up $(n=4)$. Of the remaining 79 participants a further 14 were excluded due to the fact that they had taken metformin during the study period as this has been shown to modulate IL6 and CRP levels $(18,19)$. Therefore, 65 participants were included in the current analysis.

\section{Anthropometric and clinical assessments}

Baseline demographic data captured at screening included age and ethnicity. Weight (to the nearest $0.1 \mathrm{~kg}$ ) and height (to the nearest $0.1 \mathrm{~cm}$ ) were measured using a stadiometer. Blood pressure was measured according to a standardised operating procedure using a calibrated sphygmomanometer and brachial inflation cuff (HEM-7200 M3, Omron Healthcare, Kyoto, Japan). Prior to screening, participants were instructed to fast for $12 \mathrm{~h}$ before the study visit. Blood glucose, HDL and LDL were measured using the Siemens Advia 1800 analyser (Surrey, UK) and HbA1C on an Arkay HA-8180 analyser (Amstelveen, Netherlands). All were analysed by the, Clinical Pathology Service, University Hospitals of Leicester.

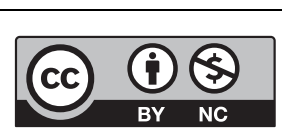

This work is licensed under a Creative Commons Attribution-NonCommercial 4.0 International License. 


\section{Biomarker measurement}

Venous (fasting) blood was collected in EDTA vacutainers, centrifuged at $1500 \boldsymbol{g}$ for $10 \mathrm{~min}$ to produce plasma, and this was then frozen at $-80^{\circ} \mathrm{C}$ for subsequent measurement of research biomarkers. Quantitative analysis of plasma for insulin was carried out using Mercodia insulin ELISA assays (Uppsala, Sweden). IL6 and CRP were analysed by electrochemoluminescence using Mesoscale Discovery assays (Mesoscale, MD, USA). All samples were analysed in duplicate, with all duplicate samples having a CV\% of $\leq 20 \%$.

\section{Accelerometer assessments}

At baseline and 6 months, patient visit accelerometer measurement was initiated during the appointment. Participants were asked to wear a GTX3 accelerometer (Actigraph, Penascola, FL, USA) on the right midaxillary line of the hip (attached via a waistband), for up to 10 consecutive days during waking hours at baseline and at follow-up. Ambulatory activity was estimated using step counts. Non-wear time was defined as a minimum of $60 \mathrm{~min}$ of continuous zero counts and valid days consisted of at least $10 \mathrm{~h}$ (600 min) of accelerometer data. Participants with at least four valid days were included in the analysis (20). The accelerometers utilised were sealed; therefore, participants could not misreport daily step count. Data were analysed using KineSoft software version 3.3.76 (Loughborough, UK).

\section{Statistical analysis}

Demographic variables are presented as means (s.e.) or median (ranges). Initially paired $t$-test analysis was carried out at 0 and 6 months to provide descriptive statistics and a comparison of the cohort at baseline and follow-up. Subsequently, regression analysis was carried out to examine the association between changes in step count (between baseline and 6 months) with changes in markers of inflammation, T2DM or CVD. Covariates age, ethnicity, baseline step count, change in BMI and change in accelerometer wear-time were selected a priori on the basis of previously reported associations with the above morbidities or estimation of step count $(21,22,23,24,25)$. Data were analysed using SPSS, version 24. No adjustments were made for multiple testing. $P$ values of $<0.05$ were considered statistically significant.

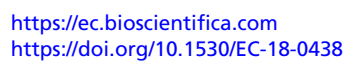

\section{Results}

Study population and paired analysis of baseline and 6-month data

Assessment of the cohort showed that 38 were white European and 27 were black or minority ethnic. The median age at baseline was 34.8 years (range 21.6-49.9). The descriptive statistics (at both baseline and 6 months) are outlined in Table 1. Paired-analysis of mean values at baseline and follow-up showed that daily step count increased by an average of 354 steps (ns). However, significant reductions in $\mathrm{HbA} 1 \mathrm{c} \%$, HbA1c $\mathrm{mmol} / \mathrm{mol}$ $(0.36 \%$ and $3.96 \mathrm{mmol} / \mathrm{mol}$, both $P \leq 0.001)$ and systolic blood pressure $(3.84 \mathrm{mmHg}, P=0.004)$ were seen at the 6-month follow-up.

Association of step count change with inflammatory and clinical markers of T2DM and CVD

An increase in daily step count was associated with a highly significant decrease in IL6 $(P=0.005)$ which represented a $0.81 \mathrm{ng} / \mathrm{L}$ reduction per 1000 steps, equating to a $13 \%$ decrease. There was also a significant reduction in CRP $(0.068 \mathrm{mg} / \mathrm{L}, P=0.033)$ which represented a $13 \%$ decrease per 1000 steps. Additionally, increased step count was associated with a significant decrease in BMI $\left(0.20 \mathrm{~kg} / \mathrm{m}^{2}, P=0.038\right)$. However, increase in step count was not associated with any other markers of T2DM and CVD (Table 2).

Table 1 Descriptive characteristics of the study population at baseline and 6 months.

\begin{tabular}{|c|c|c|c|}
\hline Characteristic & $\begin{array}{c}\text { Mean value } \\
\text { at BL }\end{array}$ & $\begin{array}{l}\text { Mean value } \\
\text { at } 6 \text { months }\end{array}$ & $P$ value \\
\hline Age, years & 34.8 & & \\
\hline Body mass index, $\mathrm{kg} / \mathrm{m}^{2}$ & $32.5(0.89)$ & $32.2(0.91)$ & 0.067 \\
\hline $\begin{array}{l}\text { Average daily steps } \\
\text { (1000s) }\end{array}$ & $6.34(0.27)$ & $6.69(0.32)$ & 0.121 \\
\hline IL6, ng/L & $6.07(0.64)$ & $6.46(0.58)$ & 0.428 \\
\hline CRP, mg/L & $5.4(0.58)$ & $5.7(0.73)$ & 0.534 \\
\hline Fasting insulin, mIU/L & $11.47(1.05)$ & $13.40(1.39)$ & 0.069 \\
\hline HOMA IR & $2.54(0.27)$ & $2.61(0.32)$ & 0.632 \\
\hline $\begin{array}{l}\text { Fasting glucose, } \\
\mathrm{mmol} / \mathrm{L}\end{array}$ & $4.8(0.06)$ & $4.9(0.06)$ & 0.058 \\
\hline HbA1C, \% & $5.7(0.04)$ & $5.4(0.04)$ & $<0.001$ \\
\hline $\mathrm{HbA} 1 \mathrm{c}, \mathrm{mmol} / \mathrm{mol}$ & $39(0.45)$ & $35(0.42)$ & $<0.001$ \\
\hline Diastolic BP, mmHg & $78(1.5)$ & $76(1.32)$ & 0.096 \\
\hline Systolic BP, mmHg & $119(1.63)$ & $115(1.53)$ & 0.004 \\
\hline $\mathrm{LDL}, \mathrm{mmol} / \mathrm{L}$ & $3.0(0.11)$ & $2.9(0.11)$ & 0.845 \\
\hline $\mathrm{HDL}, \mathrm{mmol} / \mathrm{L}$ & $1.5(0.056)$ & $1.5(0.08)$ & 0.514 \\
\hline
\end{tabular}

All values are mean (S.E.). $P$ values of $<0.05$ are in italics. $P$ values test for a difference between data at baseline and 6 months and were estimated using $t$-tests for continuous variables. Missing values for continuous variables: 4 fasting glucose, $3 \mathrm{LDL}, 3 \mathrm{HDL}, 1 \mathrm{HbA} 1 \mathrm{c} \%$ and $1 \mathrm{HbA} 1 \mathrm{c} \mathrm{mmol} / \mathrm{mol}$.

This work is licensed under a Creative Commons Attribution-NonCommercial 4.0 International License. 
Table 2 Adjusted linear regression comparing step count change (1000 steps) with changes in markers of inflammation, T2DM and CVD.

\begin{tabular}{l} 
Characteristic \\
\hline$\Delta$ IL6, $\mathrm{ng} / \mathrm{L}$ \\
$\Delta$ CRP, $\mathrm{mg} / \mathrm{L}$ \\
$\Delta$ Fasting insulin, $\mathrm{mIU} / \mathrm{L}$ \\
$\Delta \mathrm{HOMA}$ IR \\
$\Delta$ Fasting glucose, $\mathrm{mmol} / \mathrm{L}$ \\
$\Delta \mathrm{HbA} 1 \mathrm{C}, \%$ \\
$\Delta \mathrm{LDL}, \mathrm{mmol} / \mathrm{L}$ \\
$\Delta \mathrm{HDL}, \mathrm{mmol} / \mathrm{L}$ \\
$\Delta$ Diastolic BP \\
$\Delta$ Systolic BP \\
$\Delta$ Body mass index, $\mathrm{kg} / \mathrm{m}^{2}$
\end{tabular}

\begin{tabular}{c}
\hline Unstandardised beta co-efficient $(95 \% \mathrm{Cl})$ \\
\hline$-0.81(-1.37,-0.25)$ \\
$-0.68(-1.31,-0.06)$ \\
$0.61(-0.68,1.90)$ \\
$0.17(-0.02,0.35)$ \\
$0.17(-0.034,0.068)$ \\
$0.04(-0.00,0.075)$ \\
$-0.027(-0.1,0.045)$ \\
$-0.011(0.07,0.09)$ \\
$0.55(-0.75,1.84)$ \\
$0.54(-1.04,2.13)$ \\
$-0.20(-0.38,-0.01)$
\end{tabular}

\begin{tabular}{c}
$\boldsymbol{P}$ value \\
\hline 0.005 \\
0.033 \\
0.348 \\
0.086 \\
0.509 \\
0.056 \\
0.455 \\
0.792 \\
0.402 \\
0.497 \\
0.038
\end{tabular}

$P$ values of $<0.05$ are in italics. Analyses were adjusted for age (at baseline), ethnicity, baseline step count, change in accelerometer wear-time and change in BMI. For analysis of $\Delta \mathrm{BMI}$ vs $\Delta$ step count adjustments for age (at baseline), ethnicity, baseline step count, change in accelerometer wear-time.

\section{Discussion}

The aim of the current study was to establish whether modest changes in ambulatory physical activity in a cohort of overweight or obese women with PCOS could modulate systemic inflammation which is an important precursor of CVD and T2DM. This study showed a $13 \%$ reduction in both IL6 and CRP with every 1000-step/day increase; however, no significant changes in clinical markers of CVD and T2DM were detected. Whilst a $13 \%$ reduction may appear modest these results suggest that within this cohort increasing step count to levels in line with NHS recommendations, i.e. from 6337 to 10,000 steps, may reduce IL6 and CRP levels by approximately one-third. Due to the fact IL6 and CRP are implicated in insulin resistance and CVD risk, downregulation of these cytokines through reaching a 10,000 step per day target may significantly reduce PCOS-related morbidity. Additionally, IL6 is involved in the pathogenesis of hyperandrogenic disorders (26); therefore, it could be postulated that greater reductions IL6 through increased step count may improve the hyperandrogenic symptoms in women with PCOS.

Although there is strong evidence that exercise, particularly vigorous exercise, can drive down chronic inflammation, studies assessing levels of inflammation with increased ambulatory activity are conflicting, with several studies showing no change in inflammatory status (27). However, the cohort in the present study represents a group with a heightened inflammatory state and therefore exercise-induced reductions in proinflammatory cytokines are likely to be more perceptible. Interestingly, the mechanisms by which physical activity (PA) reduces systemic inflammation have not been fully elucidated. One proposed mechanism suggests that PA

$\begin{array}{lr}\text { https://ec.bioscientifica.com } & \text { @ } 2018 \text { The authors } \\ \text { https://doi.org/10.1530/EC-18-0438 } & \text { Published by Bioscientifica Ltd }\end{array}$

reduces visceral fat levels which in turn causes a reduction in the release of adipokines such as IL6 (reviewed by (28)). There is also some evidence that PA reduces expression of CD14+ and CD16 positive monocytes cells which are potent producers of inflammatory cytokines (29).

Whilst a plethora of reports have shown an increased risk of CVD and T2DM with PCOS, meta-analysis has not detected an excess risk of cardiovascular-related mortality (30). However, both CVD and T2DM in PCOS contribute to higher rates of complications during pregnancy (31) are a considerable economic expense (32) and are likely to have a negative impact on quality of life; therefore, strategies to reduce CVD and T2DM rates in women with PCOS remain an important target.

Whilst not a primary outcome, $t$-test analysis of the cohort at baseline and again at 6 months showed that both systolic blood pressure and HbA1c had significantly reduced (Table 1). It is likely these improvements are in response to the lifestyle advice (particularly nutritional advice) provided as part of the original randomised control trial (15).

\section{Strengths and limitations}

Accelerometry has been shown to be an accurate and objective measurement of physical activity (33); however, it does not account for uptake of activities not compatible with accelerometer wear for example swimming. We experienced poor compliance with accelerometer wear within this study with 79 of 161 participants providing incomplete data at either baseline or 6 months. As this is a secondary analysis of a study designed to test a different primary hypothesis some measurement bias and residual confounding is likely. Finally, the regression data presented in Table 2 merely shows a correlation between step count and IL6/CRP and does not prove causation. 


\section{Conclusions}

This study provides evidence that moderate increases in daily step count can significantly decrease levels of IL6 and CRP in women with PCOS, although clinical markers of T2DM and CVD did not show a significant improvement. This work suggests that interventions that successfully increase step count in line with NHS recommendations may prove efficacious in reducing PCOS-related morbidity.

\section{Declaration of interest}

The authors declare that there is no conflict of interest that could be perceived as prejudicing the impartiality of the research reported.

\section{Funding}

This research was supported by the National Institute for Health Research (NIHR) Leicester Biomedical Research Centre, the NIHR Collaboration for Leadership in Applied Health Research and Care - East Midlands (NIHR CLAHRC - EM) and an Early Career Grant from the Society for Endocrinology (Dr Hamid Mani). The views expressed are those of the authors and not necessarily those of the above mentioned organisations.

\section{Author contribution statement}

Conceptualization: M A W, S J R and H M. Methodology: M A W, H M, M J D, H L W, K K, D R W, T Y and C L E. Formal analysis: M A W, S J R and D H B. Data curation: M A W, S J R, D R W, T Y, CLE and H M, Writing original draft: $M A$ W. Editing and reviewing: $M J D, K K, H M, H L W$ and $C L E$.

\section{Acknowledgements}

The authors would like to thank the SUCCESS clinical trial team, in particular, Paul Bray, Lesley Bryan and Jane Brela. They would also like to thank Dr Joseph Henson for reviewing the manuscript.

\section{References}

1 March WA, Moore VM, Willson KJ, Phillips DI, Norman RJ \& Davies MJ. The prevalence of polycystic ovary syndrome in a community sample assessed under contrasting diagnostic criteria. Human Reproduction 201025 544-551. (https://doi.org/10.1093/ humrep/dep399)

2 Carmina E \& Lobo RA. Use of fasting blood to assess the prevalence of insulin resistance in women with polycystic ovary syndrome. Fertility and Sterility 200482 661-665. (https://doi.org/10.1016/j. fertnstert.2004.01.041)

3 Ehrmann DA, Barnes RB, Rosenfield RL, Cavaghan MK \& Imperial J. Prevalence of impaired glucose tolerance and diabetes in women with polycystic ovary syndrome. Diabetes Care 199922 141-146. (https://doi.org/10.2337/diacare.22.1.141)

4 de Groot PC, Dekkers OM, Romijn JA, Dieben SW \& Helmerhorst FM. PCOS, coronary heart disease, stroke and the influence of obesity: a systematic review and meta-analysis. Human Reproduction Update 201117 495-500. (https://doi.org/10.1093/humupd/dmr001)

5 Apridonidze T, Essah PA, Iuorno MJ \& Nestler JE. Prevalence and characteristics of the metabolic syndrome in women with polycystic ovary syndrome. Journal of Clinical Endocrinology and Metabolism 2005 90 1929-1935. (https://doi.org/10.1210/jc.2004-1045)
6 Mani H, Levy MJ, Davies MJ, Morris DH, Gray LJ, Bankart J, Blackledge H, Khunti K \& Howlett TA. Diabetes and cardiovascular events in women with polycystic ovary syndrome: a 20-year retrospective cohort study. Clinical Endocrinology 201378 926-934. (https://doi.org/10.1111/cen.12068)

7 Escobar-Morreale HF, Luque-Ramirez M \& Gonzalez F. Circulating inflammatory markers in polycystic ovary syndrome: a systematic review and metaanalysis. Fertility and Sterility 2011951048. e1-2-1058.e1-2.

8 Peng Z, Sun Y, Lv X, Zhang H, Liu C \& Dai S. Interleukin-6 levels in women with polycystic ovary syndrome: a systematic review and meta-analysis. PLOS ONE 201611 e0148531. (https://doi. org/10.1371/journal.pone.0148531)

9 Lin YS, Tsai SJ, Lin MW, Yang CT, Huang MF \& Wu MH. Interleukin-6 as an early chronic inflammatory marker in polycystic ovary syndrome with insulin receptor substrate-2 polymorphism. American Journal of Reproductive Immunology 201166 527-533. (https://doi. org/10.1111/j.1600-0897.2011.01059.x)

10 Senn JJ, Klover PJ, Nowak IA \& Mooney RA. Interleukin-6 induces cellular insulin resistance in hepatocytes. Diabetes 200251 3391-3399. (https://doi.org/10.2337/diabetes.51.12.3391)

11 Tsigos C, Papanicolaou DA, Kyrou I, Defensor R, Mitsiadis CS \& Chrousos GP. Dose-dependent effects of recombinant human interleukin-6 on glucose regulation. Journal of Clinical Endocrinology and Metabolism 199782 4167-4170. (https://doi.org/10.1210/ jcem.82.12.4422)

12 NACB LMPG Committee Members, Myers GL, Christenson RH, Cushman M, Ballantyne CM, Cooper GR, Pfeiffer CM, Grundy SM, Labarthe DR, Levy D, et al. National Academy of Clinical Biochemistry Laboratory Medicine Practice guidelines: emerging biomarkers for primary prevention of cardiovascular disease. Clinical Chemistry 200955 378-384. (https://doi.org/10.1373/ clinchem.2008.115899)

13 Giallauria F, Palomba S, Maresca L, Vuolo L, Tafuri D, Lombardi G, Colao A, Vigorito C \& Francesco O. Exercise training improves autonomic function and inflammatory pattern in women with polycystic ovary syndrome (PCOS). Clinical Endocrinology 200869 792-798. (https://doi.org/10.1111/j.1365-2265.2008.03305.x)

14 Hillsdon M \& Thorogood M. A systematic review of physical activity promotion strategies. British Journal of Sports Medicine 199630 84-89. (https://doi.org/10.1136/bjsm.30.2.84)

15 Mani H, Chudasama Y, Hadjiconstantinou M, Bodicoat DH, Edwardson C, Levy M, Gray LJ, Barnett J, Daly H, Howlett TA, et al. Structured education programme for women with polycystic ovary syndrome: a randomised controlled trial. Endocrine Connections 2018 7 26-35. (https://doi.org/10.1530/EC-17-0274)

16 Fauser BC, Tarlatzis BC, Rebar RW, Legro RS, Balen AH, Lobo R, Carmina E, Chang J, Yildiz BO, Laven JS, et al. Consensus on women's health aspects of polycystic ovary syndrome (PCOS): the Amsterdam ESHRE/ASRM-Sponsored 3rd PCOS Consensus Workshop Group. Fertility and Sterility 201297 28.e25-38.e25.

17 'NICE'. BMI: preventing ill health and premature death in black, Asian and other minority ethnic groups. Public health guideline (PH46) 2018. 2013.

18 Luque-Ramirez M \& Escobar-Morreale HF. Treatment of polycystic ovary syndrome (PCOS) with metformin ameliorates insulin resistance in parallel with the decrease of serum interleukin-6 concentrations. Hormone and Metabolic Research 201042 815-820. (https://doi.org/10.1055/s-0030-1262855)

19 Morin-Papunen L, Rautio K, Ruokonen A, Hedberg P, Puukka M \& Tapanainen JS. Metformin reduces serum C-reactive protein levels in women with polycystic ovary syndrome. Journal of Clinical Endocrinology and Metabolism 200388 4649-4654. (https://doi. org/10.1210/jc.2002-021688)

20 Troiano RP, Berrigan D, Dodd KW, Masse LC, Tilert T \& McDowell M. Physical activity in the United States measured by accelerometer. 
Medicine and Science in Sports and Exercise 200840 181-188. (https:// doi.org/10.1249/mss.0b013e31815a51b3)

21 Halter JB, Musi N, McFarland Horne F, Crandall JP, Goldberg A, Harkless L, Hazzard WR, Huang ES, Kirkman MS, et al. Diabetes and cardiovascular disease in older adults: current status and future directions. Diabetes 201463 2578-2589. (https://doi.org/10.2337/ db14-0020)

22 Gholap N, Davies M, Patel K, Sattar N \& Khunti K. Type 2 diabetes and cardiovascular disease in South Asians. Primary Care Diabetes 20115 45-56. (https://doi.org/10.1016/j.pcd.2010.08.002)

23 Kopp HP, Kopp CW, Festa A, Krzyzanowska K, Kriwanek S, Minar E, Roka R \& Schernthaner G. Impact of weight loss on inflammatory proteins and their association with the insulin resistance syndrome in morbidly obese patients. Arteriosclerosis, Thrombosis, and Vascular Biology 200323 1042-1047. (https://doi.org/10.1161/01. ATV.0000073313.16135.21)

24 Vickers AJ \& Altman DG. Statistics notes: analysing controlled trials with baseline and follow up measurements. BMJ 2001323 1123-1124. (https://doi.org/10.1136/bmj.323.7321.1123)

25 Herrmann SD, Barreira TV, Kang M \& Ainsworth BE. Impact of accelerometer wear time on physical activity data: a NHANES semisimulation data approach. British Journal of Sports Medicine 201448 278-282. (https://doi.org/10.1136/ bjsports-2012-091410)

26 Villuendas G, San Millan JL, Sancho J \& Escobar-Morreale HF. The -597 G-->A and -174 G-->C polymorphisms in the promoter of the IL6 gene are associated with hyperandrogenism. Journal of Clinical Endocrinology and Metabolism 200287 1134-1141.
27 Morettini M, Storm F, Sacchetti M, Cappozzo A \& Mazza C. Effects of walking on low-grade inflammation and their implications for Type 2 Diabetes. Preventive Medicine Reports 20152 538-547. (https://doi. org/10.1016/j.pmedr.2015.06.012)

28 Gleeson M, Bishop NC, Stensel DJ, Lindley MR, Mastana SS \& Nimmo MA. The anti-inflammatory effects of exercise: mechanisms and implications for the prevention and treatment of disease. Nature Reviews Immunology 201111 607-615. (https://doi.org/10.1038/nri3041)

29 Timmerman KL, Flynn MG, Coen PM, Markofski MM \& Pence BD. Exercise training-induced lowering of inflammatory (CD14+CD16+) monocytes: a role in the anti-inflammatory influence of exercise? Journal of Leukocyte Biology $2008 \mathbf{8 4}$ 1271-1278. (https://doi. org/10.1189/jlb.0408244)

30 Pierpoint T, McKeigue PM, Isaacs AJ, Wild SH \& Jacobs HS. Mortality of women with polycystic ovary syndrome at long-term follow-up. Journal of Clinical Epidemiology 199851 581-586. (https://doi. org/10.1016/S0895-4356(98)00035-3)

31 Homburg R. Pregnancy complications in PCOS. Best Practice and Research: Clinical Endocrinology and Metabolism 200620 281-292. (https://doi.org/10.1016/j.beem.2006.03.009)

32 Azziz R, Marin C, Hoq L, Badamgarav E \& Song P. Health care-related economic burden of the polycystic ovary syndrome during the reproductive life span. Journal of Clinical Endocrinology and Metabolism 200590 4650-4658. (https://doi.org/10.1210/jc.2005-0628)

33 Chen KY, Bassett DR Jr. The technology of accelerometry-based activity monitors: current and future. Medicine and Science in Sports and Exercise 200537 S490-S500. (https://doi.org/10.1249/01. mss.0000185571.49104.82)

Received in final form 7 November 2018

Accepted 21 November 2018

Accepted Preprint published online 22 November 2018

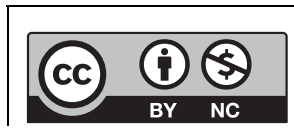

This work is licensed under a Creative Commons Attribution-NonCommercial 4.0 International License. 